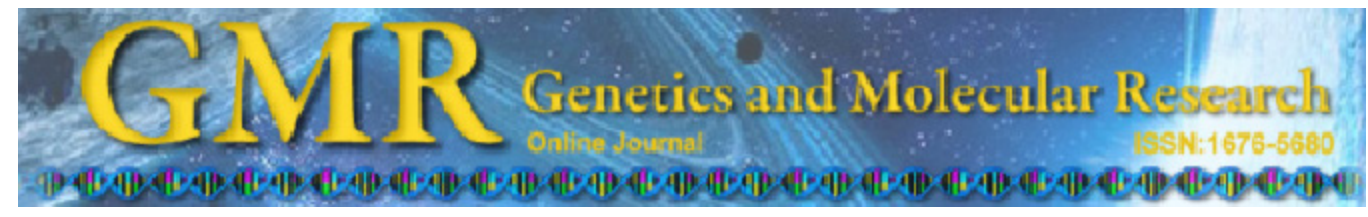

\title{
Genetic characterization of hatchery populations of Korean spotted sea bass (Lateolabrax maculatus) using multiplex polymerase chain reaction assays
}

\author{
H.S. An ${ }^{1}$, H.Y. Kim², J.B. Kim², D.S. Chang' ${ }^{2}$ K.D. Park ${ }^{3}$, J.W. Lee ${ }^{4}$, \\ J.I. Myeong ${ }^{4}$ and C.M. An ${ }^{1}$ \\ ${ }^{1}$ Biotechnology Research Division, \\ National Fisheries Research and Development Institute, Busan, Korea \\ ${ }^{2}$ Fisheries Resources and Environment Division, \\ Southwest Sea Fisheries Research Institute, \\ National Fisheries Research and Development Institute, Yeosu, Korea \\ ${ }^{3}$ Fishery Resource Research Institute, Gyongsangnamdo, Korea \\ ${ }^{4}$ Aquaculture Management Division, \\ National Fisheries Research and Development Institute, Busan, Korea \\ Corresponding author: H.S. An \\ E-mail: hsan97@korea.kr
}

Genet. Mol. Res. 13 (3): 6701-6715 (2014)

Received January 23, 2014

Accepted May 29, 2014

Published August 28, 2014

DOI http://dx.doi.org/10.4238/2014.August.28.14

\begin{abstract}
The spotted sea bass, Lateolabrax maculatus, is an important commercial and recreational fishery resource in Korea. Aquacultural production of this species has increased because of recent resource declines, growing consumption, and ongoing governmentoperated stock release programs. Therefore, the genetic characterization of hatchery populations is necessary to maintain the genetic diversity of this species and to develop more effective aquaculture practices. In this study, the genetic diversity and structure of three cultured populations in Korea were assessed using multiplex assays with 12 highly polymorphic microsatellite loci; 144 alleles were identified. The number of alleles per locus ranged from 6 to 28, with an average of 13.1. The mean observed
\end{abstract}


and expected heterozygosities were 0.724 and 0.753 , respectively. Low levels of inbreeding were detected according to the inbreeding coefficient (mean $F_{\text {IS }}=0.003-0.073$ ). All hatchery populations were significantly differentiated from each other (overall fixation index $\left(F_{\mathrm{ST}}\right)=0.027, \mathrm{P}<$ 0.01 ), and no population formed a separate cluster. Pairwise multilocus $F_{\text {ST }}$ tests, estimates of genetic distance, mantel test, and principal component analyses did not show a consistent relationship between geographic and genetic distances. These results could reflect the exchange of breeds and eggs between hatcheries and/or genetic drift due to intensive breeding practices. For optimal resource management, the genetic variation of hatchery stocks should be monitored and inbreeding controlled within the spotted sea bass stocks that are being released every year. This genetic information will be useful for the management of both $L$. maculatus fisheries and the aquaculture industry.

Key words: Genetic diversity; Genetic differentiation; Hatchery population of Korean spotted sea bass (Lateolabrax maculatus); Microsatellite loci; Multiplex polymerase chain reaction (PCR) assay

\section{INTRODUCTION}

The Korean spotted sea bass, Lateolabrax maculatus (Perciformes: Moronidae), is widely distributed along the Korean coast with the borders of Vietnam and China (Shao et al., 2009). L. maculatus has been designated as a congeneric species of L. japonicus based on morphological traits, but it was recently redescribed as a reef-associated fish species that is characterized by its distinctive characteristics including many clear black dots on the lateral body region (Yokogawa and Seki, 1995; Kim and Jun, 1997). In Pacific Asia, L. maculatus is one of the most important commercial fishery species. However, its natural population has been declining continuously for two decades in Korea (Ministry for Food, Agriculture, Forestry, and Fisheries, 2009). In response to decreased natural resources in the face of increasing demand, the aquacultural production of spotted sea bass has increased since the early 2000 s, and it has rapidly developed in the past decade. Furthermore, the Korean government has sponsored artificial spotted sea bass seed release for coastal spotted sea bass resource enhancement, and more than one million spotted sea bass seeds reared in hatcheries were released into the Korean coastal sea areas in 2012.

Restocking and stock enhancement have been used as tools to recover stocks of commercially overexploited marine resources in several countries (Støttrup and Sparrevohn, 2007). However, the massive releases of hatchery-produced fish have raised concerns about their genetic effects on wild populations. Hatchery fish may have a reduced genetic variability, and this may eventually lower the genetic diversity and could potentially alter the genetic structure of natural populations (Taniguchi, 2003). Hence, hatchery production of spotted sea bass raises concerns regarding the maintenance of genetic diversity among cultured stocks. Therefore, an investigation of the genetic variation in cultured spotted sea bass stocks is urgently needed for successful hatchery management, the production of high-quality spotted sea bass, and to avoid reductions in the genetic variation in aquaculture stocks. Investigating the genetic diversity and population structure of species after overexploitation and/or introgression have occurred fails to maximize the potential for using this knowledge as a tool to aid in the development of policies that adequately protect biodiversity in the wild populations from anthropogenic influences. 
The monitoring of genetic variation among marine resources can be achieved by molecular genetic analysis (Ward, 2006). Molecular methods that utilize polymerase chain reaction (PCR) and nucleotide sequence determination overcome many of the limitations of phenotypic methods (Choi and Kim, 2012; Lee and Hur, 2012). Most importantly, microsatellites emerged as molecular markers with the finest resolution to label populations and individuals because of their high variability, abundance, neutrality, codominant inheritance, and good reproducibility (Tautz, 1989; Kim et al., 2013). Microsatellite genotyping has proved to be a powerful tool in studies of genetic variation in many marine species (An et al., 2012; Han et al., 2012; Hong et al., 2012). However, despite the commercial importance and history of stocking practices of spotted sea bass in Korea, genetic studies on spotted sea bass using DNA markers have been relatively rare. The genetic structuring of Northwestern Pacific populations has been analyzed using mitochondrial DNA polymorphism (Liu et al., 2009), and microsatellite markers have been reported from L. maculatus in China (Shao et al., 2009). Quite recently, one wild population and one hatchery population in Korea were analyzed with eight polymorphic markers (An et al., 2013). No further data about the genetic diversity of cultured stocks in different regions are available. Furthermore, the increasing demand for routinely performing population genetic studies in L. maculatus to support optimum management and selection programs prompts the development of robust and low-cost genetic tagging tools. Microsatellite multiplex PCR by successive technical advances, in which several markers are simultaneously amplified in the same reaction, is used to increase the amount of information generated per assay and to reduce consumable and labor costs (Henegariu et al., 1997; Neff et al., 2000).

In this study, the genetic diversity and relationships within and between cultured pop-

ulations of L. maculatus from different regions in Korea were investigated using multiplex PCR assays with 12 microsatellite markers. This study will provide useful data for effective monitoring and management of spotted sea bass populations as well as for the implementation of stock-enhancing programs.

\section{MATERIAL AND METHODS}

\section{Sample collection and DNA extraction}

For the analysis, 130 spotted sea basses (L. maculatus) were collected from three coastal locations in Korea between June and July 2013 (Figure 1). To cover the main aquaculture areas, three hatchery populations were sampled from three different areas in Yeosu (YS; 30 individuals) and Namhae (NH; 50 individuals) in the southern coastal areas and Hwaseong (HS; 50 individuals) in the western coastal areas (Table 1). The samples from hatchery-reared populations were acquired from a population of hatchery-reared offspring from small broodstocks composed of hatchery-produced adults. Although the original ancestors of the hatchery spotted sea bass were collected locally and the hatchery populations had been reared continuously, no detailed records of their founding and maintenance were available.

Caudal fin samples were collected from fresh specimens and immediately stored in 99.9\% ethanol until DNA preparation. Genomic DNA for genotyping was extracted from fin clips of each sample using an automated DNA extraction system, MagExtractor MFX-2100 (TOYOBO, Osaka, Japan), with a MagExtractor-Genomic DNA Purification Kit (TOYOBO). The genomic DNA extracted was kept at $-20^{\circ} \mathrm{C}$ until genotyping. 


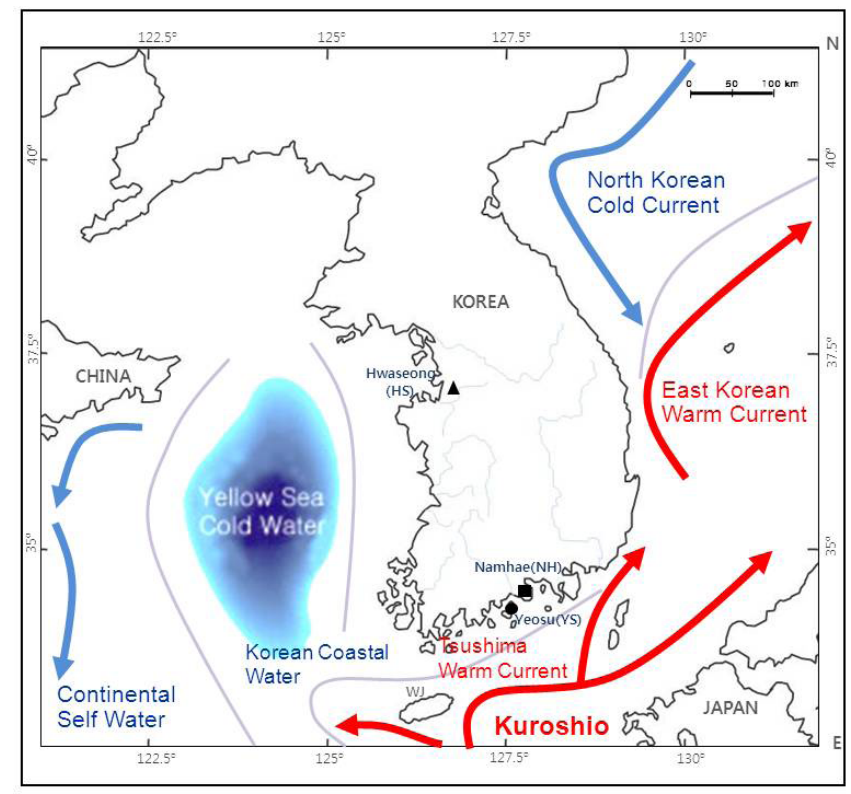

Figure 1. Approximate locations of the three hatchery population sample sites of Lateolabrax maculatus that were used in this study. The abbreviations are as follows: $\mathrm{YS}=\mathrm{Yeosu}$; $\mathrm{NH}=$ Namhae; and HS = Hwaseong.

Table 1. Collection details for three hatchery populations of Korean spotted sea bass, Lateolabrax maculatus.

\begin{tabular}{llcc}
\hline Sampling area (abbreviation) & Sample locality & Sample size & Collection date \\
\hline Yeosu (YS) & South Sea; $34^{\circ} 45^{\prime} \mathrm{N}, 127^{\circ} 39^{\prime} \mathrm{E}$ & 30 & June 2013 \\
Namhae (NH) & South Sea; $34^{\circ} 48^{\prime} \mathrm{N}, 127^{\circ} 54^{\prime} \mathrm{E}$ & 50 & June 2013 \\
Hwaseong (HS) & West Sea; $37^{\circ} 11^{\prime} \mathrm{N}, 126^{\circ} 50^{\prime} \mathrm{E}$ & 50 & July 2013 \\
\hline
\end{tabular}

\section{Multiplex PCR design and microsatellite genotyping}

L. maculatus is closely related to a congeneric species, Lateolabrax japonicus based on morphological traits. Thus, 18 polymorphic microsatellite loci for L. maculatus (Shao et al., 2009) and 22 polymorphic cross-specific microsatellite loci for L. japonicus (Jiang et al., 2007) were tested to develop a multiplex PCR technique using eight wild spotted sea bass individuals. PCR was conducted in $25-\mu \mathrm{L}$ reactions containing $12.5 \mu \mathrm{L} 2 \mathrm{X}$ Multiplex PCR Pre-Mix (SolGent, Daejeon, Korea; Cat. No. SMP01-P096), 100 ng template DNA, and 10 pmol each primer, using an ABI 9700 Thermal Cycler System (Applied Biosystems, Foster City, CA, USA). PCRs were run for $15 \mathrm{~min}$ at $95^{\circ} \mathrm{C}$ followed by 30 cycles of $20 \mathrm{~s}$ at $95^{\circ} \mathrm{C}$, $40 \mathrm{~s}$ at $54^{\circ} \mathrm{C}$, and $1 \mathrm{~min}$ at $72^{\circ} \mathrm{C}$ before a 3 -min final extension at $72^{\circ} \mathrm{C}$. PCR products were separated on a $3 \%$ agarose gel to check their sizes. Initially we selected a set of 17 candidate microsatellite loci on the basis of their good amplification quality and the variation in the size of the resulting amplicons for primary development. Each forward primer was 5'-end-labeled with 6-FAM, NED, and HEX dyes (Applied Biosystems), and the eight samples were multiplexed for genotyping. The resulting mixture was analyzed using an ABI 3130 Prism Genetic 
Analyzer (Applied Biosystems). The alleles from the raw data were analyzed using GeneMapper (ver. 4.0; Applied Biosystems). Finally, on the basis of the number of alleles per locus $\left(N_{\mathrm{A}}\right)$ in eight individuals, similar DNA amplification properties under multiplex PCR conditions, and allele range size, 12 microsatellite loci (Lama07, Lama36, Lama38, Lama40, Lama42, Lama44, Ljapo38, Ljapo44, Ljapo46, Ljapo48, Ljapo93, and Ljapo138) were selected for genotyping in PCR-based multiplex panels (Table 2). For this group of loci, optimal amplification conditions were established, mostly with respect to annealing temperatures $(52,54,56$, and $60^{\circ} \mathrm{C}$ ). The results were evaluated, and this process was optimized until clear peaks for each locus were obtained. Four PCR-based multiplex systems were used for genotyping. The 12 microsatellite loci were placed into one of four three-plex PCR panels with an annealing temperature of $54^{\circ} \mathrm{C}$ on the basis of allelic size variation: 1) Lama07, Lama36, and Ljapo138; 2) Lama38, Lama40, and Lama42; 3) Lama44, Ljapo48, and Ljapo93; and 4) Ljapo38, Ljapo44, and Ljapo46.

Four three-plex PCR amplifications were performed with 130 spotted sea bass individuals using an ABI 9700 Thermal Cycler System (Applied Biosystems). The PCR conditions and thermocycling profiles described above were used. For genotyping, $1 \mu \mathrm{L}$ PCR product was combined with formamide and a GeneScan-500 HD ROX size standard (Applied Biosystems) and subsequently electrophoresed using an ABI PRISM 3130 Automated DNA Sequencer (Applied Biosystems).

Table 2. Twelve microsatellite loci sequences for the hatchery spotted sea bass (Lateolabrax maculatus) populations used in this study. Core repeats and their specific annealing temperatures used in the multiplex polymerase chain reaction amplification assays are included.

\begin{tabular}{|c|c|c|c|c|}
\hline Locus & Primer sequence $\left(5^{\prime}-3^{\prime}\right)$ & $\mathrm{Ta}\left({ }^{\circ} \mathrm{C}\right)$ & Repeats & Accession No \\
\hline Lama07 & $\begin{array}{l}\text { F: AAAGGGTTGAAAATCCGTGG ned } \\
\text { R: CAGGAGGTAATAAAACAGGGCTA }\end{array}$ & $54(54)$ & $(\mathrm{CA})_{13} \mathrm{~N}(\mathrm{AC})_{12}$ & EU090737 \\
\hline Lama36 & $\begin{array}{l}\text { F: CTAAAGGACCACAAGATACACG hex } \\
\text { R: ACTCAGGCTCAAACCAGACA }\end{array}$ & $54(54)$ & $(\mathrm{AC})_{13}$ & EU090766 \\
\hline Lama38 & $\begin{array}{l}\text { F: ACAAAACTCATCCATCAAGCAG ned } \\
\text { R: AGTGTCCACGGAGACGGTAA }\end{array}$ & $54(54)$ & $(\mathrm{GT})_{11}$ & EU090768 \\
\hline Lama40 & $\begin{array}{l}\text { F: TCTAAGTAGGCTTGGCTGTC fam } \\
\text { R: TATCTGAAACCGTCTCCGTA }\end{array}$ & $52(54)$ & $(\mathrm{TG})_{12}$ & EU090770 \\
\hline Lama42 & $\begin{array}{l}\text { F: GTATTTCACTATCCCATCCTG hex } \\
\text { R: TATTGTTGCTCTTCCTCCTC }\end{array}$ & $50(54)$ & $(\mathrm{AC})_{15}$ & EU090772 \\
\hline Lama44 & $\begin{array}{l}\text { F: GGGCAGTAATTGGTGAGGGA ned } \\
\text { R: TCTTCAGGGCAAAAGGTGGT }\end{array}$ & $54(54)$ & $(\mathrm{GT})_{16}$ & EU090774 \\
\hline Ljapo38 & $\begin{array}{l}\text { F: TATCGGTGAAAACCTTGAAA hex } \\
\text { R: TAGCACTTGCCAGTATCCC }\end{array}$ & $57(54)$ & $(\mathrm{GT})_{22}$ & EF010957 \\
\hline Ljapo44 & $\begin{array}{l}\text { F: GGGCTGGTGACATTGGAT ned } \\
\text { R: TCTGTGTTGGCGTGGAAA }\end{array}$ & $60(54)$ & $\left.(\mathrm{TG})_{11} \mathrm{AGAA} \mathrm{AG}\right)_{4}$ & EF010954 \\
\hline Ljapo46 & $\begin{array}{l}\text { F: TGAAATAAACTGATGGATAGATA fam } \\
\text { R: CGATGGATTCAAGACCTC }\end{array}$ & $51(54)$ & $(\mathrm{GT})_{21} \mathrm{~A}(\mathrm{TG})_{4}(\mathrm{CA})_{3}$ & EF010955 \\
\hline Ljapo48 & $\begin{array}{l}\text { F: AACGACTGTCTTCACTTGGT hex } \\
\text { R: TGAGAGATTGTCATCACGG }\end{array}$ & $55(54)$ & $(\mathrm{TG})_{9} \mathrm{~T}(\mathrm{TG})_{11} \mathrm{CGCG}(\mathrm{TG})_{3}$ & EF010956 \\
\hline Ljapo93 & $\begin{array}{l}\text { F: CAGGTGTCATCTTCGTGC fam } \\
\text { R: CTGCTGTGTATCCTTCGC }\end{array}$ & $59(54)$ & $(\mathrm{GA})_{6}(\mathrm{GT})_{9}$ & EF010946 \\
\hline Ljapo138 & $\begin{array}{l}\text { F: CAGACGAAACTCTTCTTCTAACA fam } \\
\text { R: TCATTTGGACAGCCTAACG }\end{array}$ & $51(54)$ & $(\mathrm{GT})_{20}$ & EF010948 \\
\hline
\end{tabular}

Ta is the multiplex annealing temperature and $(\mathrm{Ta})$ is the original annealing temperature.

\section{Data analysis}

Possible null alleles and genotyping errors caused by stuttering and/or large-allele 
dropout were tested using MICRO-CHECKER (1000 randomizations; van Oosterhout et al., 2004). Scoring and human error were estimated by duplicate analyses. Because the conclusion drawn from microsatellite loci strongly depends on their neutrality, the data were also tested to determine whether one or more microsatellites were under selection using the LOSITAN software (Antao et al., 2008), which is a selection-detection workbench based on a well-evaluated fixation index $\left(F_{\mathrm{ST}}\right)$-outlier detection method. The software calculated $F_{\mathrm{ST}}$ values and heterozygosity for each locus according to Weir and Cockerham (1984) and expected $F_{\mathrm{ST}}$ values for each locus weighted by its heterozygosity. Simulated distributions of $F_{\mathrm{ST}}$ values conditional on heterozygosity under a neutral model were obtained and compared with the observed $F_{\text {ST }}$ values to identify potential outlier loci.

The genetic diversity of each sample was performed with the FSTAT ver. 2.9.3.2 software (http://www2.unil.ch/popgen/softwares/fstat.htm). The genetic parameters were the $N_{\mathrm{A}}$, the allelic richness $\left(A_{\mathrm{R}}\right)$, which is $N_{\mathrm{A}}$ corrected for the sample size applying the rarefaction index (El Mousadik and Petit, 1996), the size range of an allele in bp, the number of observed unique alleles $(U)$, the observed heterozygosity $\left(H_{\mathrm{O}}\right)$, the expected heterozygosity $\left(H_{\mathrm{E}}\right)$, and the polymorphic information content (PIC), which is an indicator of the utility of the marker for linkage or population genetic studies; these parameters were calculated using CERVUS version 3.0 (http://www.fieldgenetics.com/pages/aboutCervus_Overview.jsp). Differences in genetic diversity parameters were identified using a nonparametric analysis (Wilcoxon signedrank test; Wilcoxon, 1945). The inbreeding coefficient ( $F_{\text {IS }}$; Weir and Cockerham, 1984) for each population and locus was calculated to address deviations from the Hardy-Weinberg equilibrium (HWE), and the significance levels were adjusted for multiple tests using the sequential Bonferroni correction (Rice, 1989). GENEPOP'007 was used for testing linkage disequilibrium to determine the extent of distortion from the independent segregation of loci. Because hatchery populations are often subjected to founder effects and bottlenecks that result in lower genetic diversity, the Bottleneck software program ver. 1.2.02 (Cornuet and Luikart, 1996) was used under the infinite allele model (IAM), stepwise-mutation model (SMM), and two-phased model of mutation with 1000 iterations to verify the existence of bottlenecks inferred by heterozygosity excess in the three samples. Significance was tested using the Wilcoxon signed-rank test (Wilcoxon, 1945).

The extent of population differentiation was examined by calculating the global multilocus $F_{\mathrm{ST}}$ values (Weir and Cockerham, 1984) and $R_{\mathrm{ST}}$ values (1000 permutations; Rousset, $1996)$. The indices of the pairwise $F_{\mathrm{ST}}$ values based on an IAM and $R_{\mathrm{ST}}$ values based on an SMM were calculated using ARLEQUIN. The $R_{\mathrm{ST}}$ index incorporates the correlation of the weighted mean allele size, which is expressed as the number of tandem repeats. Significance levels were evaluated after the sequential Bonferroni adjustment of critical probabilities (Rice, 1989).

Hierarchical analysis of molecular variance (AMOVA) (Excoffier et al., 1992) was used to partition genetic variance among subsamples within groups and among groups using ARLEQUIN ver. 3.0 (Excoffier et al., 2005), and the significances of the AMOVA components were tested using 1000 permutations. The strength of the relationships among the geographical populations was estimated from the genetic distances based on the chord distance, $D_{\mathrm{CE}}$, between all pairs of populations (Cavalli-Sforza and Edwards, 1967). The correlation between the genetic and geographic distances was evaluated using the Mantel test, and genetic relationships between populations were evaluated using the principal component analysis (PCA) with 
GenAlEx 6.5 (http://biology.anu.edu.au/GenAlEx/Welcome.html).

\section{RESULTS}

\section{Multiplex PCR optimization}

The development of the genotyping tool consisted of progressive selections to refine the PCR conditions of the 40 microsatellite loci in L. maculatus and L. japonicus, and a successful set of 12 loci was finally obtained. Most loci were amplified in eight individuals of $L$. maculatus. The 17 microsatellites preselected for multiplex PCR had good amplification quality and covered an optimal range of product lengths. The other 23 loci were discarded because of inappropriate product lengths. Crosschecking was performed on the 17 candidate primer pairs and was aimed at assessing primer suitability for multiplex PCR conditions. From the 17 preselected loci, the 12 primers with high polymorphism were selected for primary development, and the other 5 primers, which had less than 5 alleles in 8 individuals, were retained as potential substitutes. Finally, a set of 12 microsatellites was chosen to establish the multiplex genotyping tool, and four three-plex PCR combinations were selected. All 12 loci selected contained dinucleotide repeats (Table 2).

\section{Genetic variability}

The genetic variability in three natural populations of $L$. maculatus (total $\mathrm{N}=130$ ) were assessed using the multiplex method with the 12 polymorphic microsatellite loci presented here. The 12 primer sets yielded variable profiles.

The MICRO-CHECKER analysis did not detect any allele scoring errors caused by stuttering or large-allele dropout, but it indicated that 5 (Lama07, Ljapo38, Ljapo46, Ljapo48, and Ljapo138) of the 12 loci examined may include null alleles, and our data demonstrated that Ljapo46 was affected by null alleles in all three population samples. The global outlier test using three populations with LOSITAN under both the IAM and SMM determined that no locus had an excessively high or low $F_{\mathrm{ST}}$ value relative to neutral expectations, indicating that there was no candidate for selection pressure. To minimize the detection of false positives, we considered one locus (Ljapo46) to have null alleles. Therefore, this locus was eliminated from subsequent analyses. No evidence of highly significant linkage disequilibrium among loci was found.

All 11 microsatellite loci were polymorphic in the three population samples of spotted sea bass, and the level of polymorphism varied among the loci. The genetic diversity of each population is presented in Table 3. A total of 144 alleles were observed, and some alleles were unique in each population. The allelic diversity was 13.1, with the $N_{\mathrm{A}}$ ranging from 6 to 28 ; no population had a diagnostic allele. The mean $A_{\mathrm{R}}$ numbers (for comparing $N_{\mathrm{A}}$ between different sample sizes) varied from 4.29 for Lama40 to 17.78 for Ljapo138. The highest value was observed for Ljapo138 in the YS sample, with values up to 19 alleles. In the three populations, 49.1 to $60.5 \%$ of the alleles were rare alleles with a frequency $<5 \%$. Rare alleles were detected at most loci and were not associated with a particular locus in any population. A high degree of polymorphism with PIC values between 0.510 and 0.891 was detected per locus (Table 3). The average gene diversity $\left(H_{\mathrm{E}}\right)$ varied between 0.571 and 0.910 , and the average $H_{\mathrm{O}}$ ranged between 0.529 and 0.918 . 


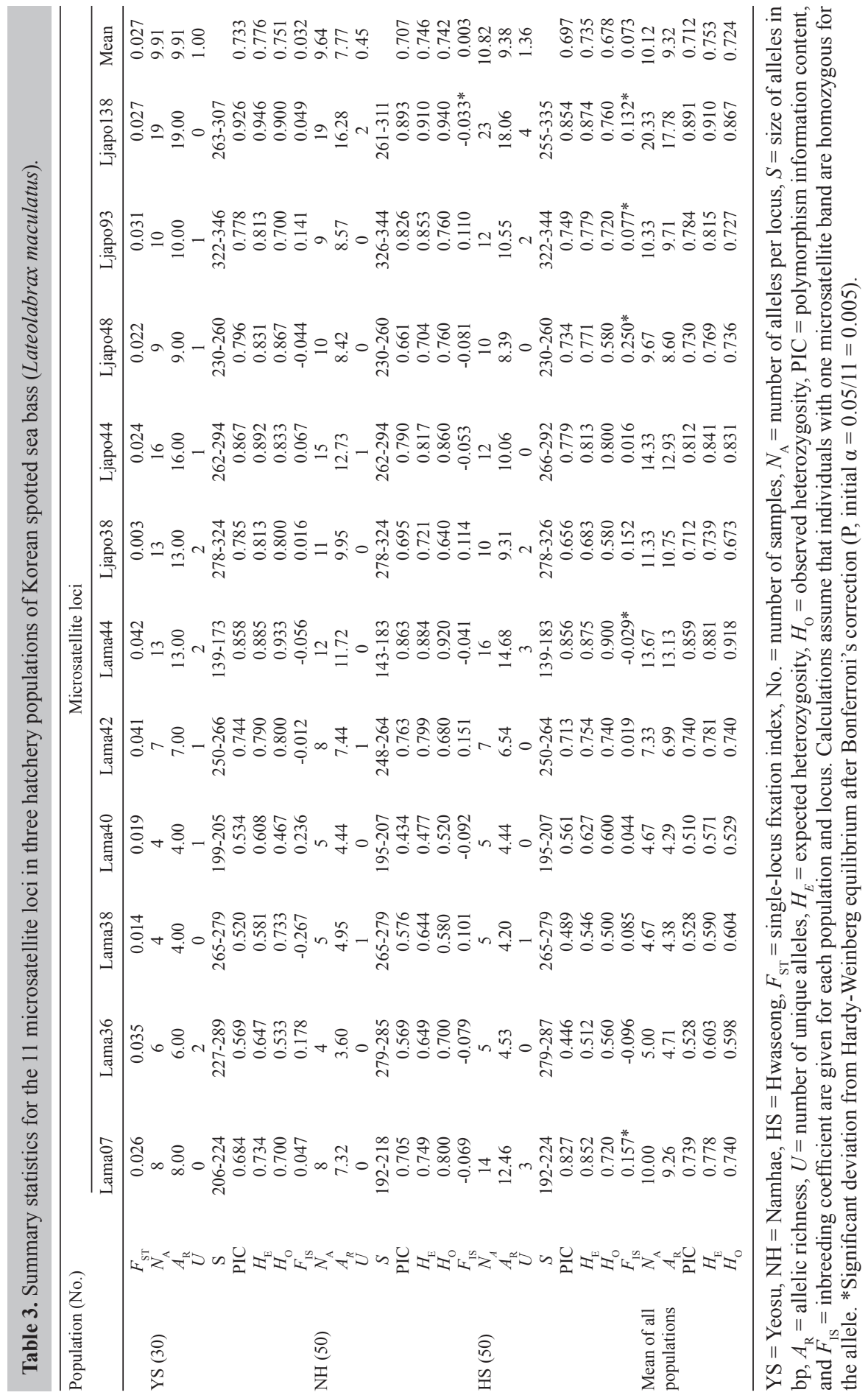


Genetic characterization of farmed Korean spotted sea bass

Table 4. Frequencies of each microsatellite allele in three hatchery populations of Korean spotted sea bass (Lateolabrax maculatus).

\begin{tabular}{|c|c|c|c|c|c|c|c|c|c|}
\hline Locus & Allele & YS & $\mathrm{NH}$ & HS & Locus & Allele & YS & $\mathrm{NH}$ & HS \\
\hline \multirow[t]{15}{*}{ Lama07 } & 192 & 0.000 & 0.010 & 0.027 & & 320 & 0.050 & 0.080 & 0.030 \\
\hline & 194 & 0.000 & 0.000 & 0.008 & & 322 & 0.050 & 0.010 & 0.100 \\
\hline & 200 & 0.000 & 0.000 & 0.004 & & 324 & 0.100 & 0.120 & 0.090 \\
\hline & 202 & 0.000 & 0.000 & 0.008 & & 326 & 0.000 & 0.000 & 0.010 \\
\hline & 206 & 0.433 & 0.250 & 0.300 & & & & & \\
\hline & 208 & 0.133 & 0.130 & 0.142 & Ljapo44 & 262 & 0.017 & 0.020 & 0.000 \\
\hline & 210 & 0.250 & 0.400 & 0.285 & & 264 & 0.017 & 0.000 & 0.000 \\
\hline & 212 & 0.000 & 0.020 & 0.015 & & 266 & 0.017 & 0.000 & 0.010 \\
\hline & 214 & 0.017 & 0.030 & 0.031 & & 268 & 0.100 & 0.160 & 0.300 \\
\hline & 216 & 0.000 & 0.030 & 0.054 & & 270 & 0.083 & 0.050 & 0.020 \\
\hline & 218 & 0.083 & 0.130 & 0.081 & & 272 & 0.250 & 0.360 & 0.190 \\
\hline & 220 & 0.050 & 0.000 & 0.019 & & 274 & 0.133 & 0.150 & 0.230 \\
\hline & 222 & 0.017 & 0.000 & 0.008 & & 276 & 0.067 & 0.070 & 0.010 \\
\hline & 224 & 0.017 & 0.000 & 0.019 & & 278 & 0.033 & 0.020 & 0.010 \\
\hline & & & & & & 280 & 0.000 & 0.050 & 0.000 \\
\hline \multirow[t]{7}{*}{ Lama36 } & 277 & 0.017 & 0.000 & 0.000 & & 282 & 0.050 & 0.020 & 0.060 \\
\hline & 279 & 0.000 & 0.010 & 0.010 & & 284 & 0.017 & 0.010 & 0.100 \\
\hline & 281 & 0.467 & 0.420 & 0.650 & & 286 & 0.117 & 0.040 & 0.040 \\
\hline & 283 & 0.367 & 0.380 & 0.260 & & 288 & 0.017 & 0.020 & 0.000 \\
\hline & 285 & 0.100 & 0.190 & 0.050 & & 290 & 0.033 & 0.010 & 0.020 \\
\hline & 287 & 0.033 & 0.000 & 0.030 & & 292 & 0.017 & 0.010 & 0.010 \\
\hline & 289 & 0.017 & 0.000 & 0.000 & & 294 & 0.033 & 0.010 & 0.000 \\
\hline \multirow[t]{7}{*}{ Lama38 } & 265 & 0.600 & 0.490 & 0.630 & Ljapo48 & 230 & 0.017 & 0.030 & 0.010 \\
\hline & 267 & 0.000 & 0.000 & 0.010 & & 232 & 0.067 & 0.090 & 0.230 \\
\hline & 273 & 0.000 & 0.040 & 0.000 & & 234 & 0.117 & 0.010 & 0.110 \\
\hline & 275 & 0.183 & 0.330 & 0.200 & & 236 & 0.000 & 0.010 & 0.010 \\
\hline & 277 & 0.183 & 0.100 & 0.150 & & 242 & 0.033 & 0.000 & 0.000 \\
\hline & 279 & 0.033 & 0.040 & 0.010 & & 250 & 0.200 & 0.230 & 0.100 \\
\hline & & & & & & 252 & 0.117 & 0.100 & 0.050 \\
\hline \multirow[t]{7}{*}{ Lama40 } & 195 & 0.000 & 0.010 & 0.020 & & 254 & 0.083 & 0.020 & 0.080 \\
\hline & 199 & 0.017 & 0.000 & 0.000 & & 256 & 0.000 & 0.010 & 0.010 \\
\hline & 201 & 0.550 & 0.700 & 0.530 & & 258 & 0.317 & 0.480 & 0.390 \\
\hline & 203 & 0.267 & 0.110 & 0.200 & & 260 & 0.050 & 0.020 & 0.010 \\
\hline & 205 & 0.167 & 0.160 & 0.240 & & & & & \\
\hline & 207 & 0.000 & 0.020 & 0.010 & Ljapo93 & 322 & 0.017 & 0.000 & 0.100 \\
\hline & & & & & & 324 & 0.000 & 0.000 & 0.010 \\
\hline \multirow[t]{10}{*}{ Lama42 } & 248 & 0.000 & 0.140 & 0.000 & & 326 & 0.100 & 0.070 & 0.060 \\
\hline & 250 & 0.200 & 0.100 & 0.180 & & 328 & 0.167 & 0.170 & 0.190 \\
\hline & 252 & 0.067 & 0.010 & 0.120 & & 330 & 0.000 & 0.000 & 0.040 \\
\hline & 256 & 0.000 & 0.020 & 0.010 & & 332 & 0.067 & 0.230 & 0.070 \\
\hline & 258 & 0.050 & 0.250 & 0.070 & & 334 & 0.367 & 0.190 & 0.410 \\
\hline & 260 & 0.300 & 0.320 & 0.410 & & 336 & 0.117 & 0.140 & 0.030 \\
\hline & 262 & 0.283 & 0.060 & 0.180 & & 338 & 0.050 & 0.070 & 0.050 \\
\hline & 264 & 0.067 & 0.100 & 0.030 & & 340 & 0.017 & 0.080 & 0.010 \\
\hline & 266 & 0.033 & 0.000 & 0.000 & & 342 & 0.000 & 0.040 & 0.020 \\
\hline & & & & & & 344 & 0.083 & 0.010 & 0.010 \\
\hline \multirow[t]{13}{*}{ Lama44 } & 139 & 0.017 & 0.000 & 0.070 & & 346 & 0.017 & 0.000 & 0.000 \\
\hline & 141 & 0.000 & 0.000 & 0.010 & & & & & \\
\hline & 143 & 0.233 & 0.230 & 0.040 & Ljapo138 & 255 & 0.000 & 0.000 & 0.010 \\
\hline & 145 & 0.183 & 0.150 & 0.050 & & 259 & 0.000 & 0.000 & 0.010 \\
\hline & 147 & 0.067 & 0.000 & 0.000 & & 261 & 0.000 & 0.100 & 0.090 \\
\hline & 149 & 0.033 & 0.020 & 0.060 & & 263 & 0.100 & 0.000 & 0.010 \\
\hline & 151 & 0.033 & 0.120 & 0.290 & & 265 & 0.017 & 0.010 & 0.020 \\
\hline & 153 & 0.067 & 0.080 & 0.030 & & 267 & 0.050 & 0.050 & 0.010 \\
\hline & 155 & 0.033 & 0.040 & 0.140 & & 269 & 0.100 & 0.190 & 0.040 \\
\hline & 157 & 0.000 & 0.050 & 0.030 & & 271 & 0.017 & 0.010 & 0.030 \\
\hline & 159 & 0.050 & 0.030 & 0.070 & & 273 & 0.050 & 0.080 & 0.020 \\
\hline & 161 & 0.067 & 0.060 & 0.080 & & 275 & 0.017 & 0.030 & 0.030 \\
\hline & 163 & 0.067 & 0.040 & 0.020 & & 277 & 0.100 & 0.080 & 0.260 \\
\hline
\end{tabular}

Continued on next page 


\begin{tabular}{|c|c|c|c|c|c|c|c|c|c|}
\hline Locus & Allele & YS & $\mathrm{NH}$ & HS & Locus & Allele & YS & $\mathrm{NH}$ & HS \\
\hline & 165 & 0.133 & 0.120 & 0.040 & & 279 & 0.100 & 0.100 & 0.210 \\
\hline & 167 & 0.000 & 0.000 & 0.040 & & 281 & 0.050 & 0.000 & 0.050 \\
\hline & 173 & 0.017 & 0.000 & 0.000 & & 283 & 0.067 & 0.000 & 0.030 \\
\hline & 179 & 0.000 & 0.000 & 0.020 & & 285 & 0.067 & 0.050 & 0.050 \\
\hline & 183 & 0.000 & 0.060 & 0.010 & & 287 & 0.017 & 0.020 & 0.010 \\
\hline & & & & & & 289 & 0.067 & 0.140 & 0.060 \\
\hline \multirow[t]{11}{*}{ Ljapo38 } & 278 & 0.067 & 0.030 & 0.040 & & 291 & 0.000 & 0.050 & 0.010 \\
\hline & 300 & 0.017 & 0.000 & 0.000 & & 293 & 0.050 & 0.000 & 0.010 \\
\hline & 302 & 0.000 & 0.000 & 0.020 & & 295 & 0.050 & 0.020 & 0.000 \\
\hline & 304 & 0.033 & 0.010 & 0.040 & & 297 & 0.050 & 0.000 & 0.010 \\
\hline & 306 & 0.017 & 0.000 & 0.000 & & 299 & 0.017 & 0.010 & 0.000 \\
\hline & 308 & 0.050 & 0.040 & 0.000 & & 301 & 0.000 & 0.020 & 0.010 \\
\hline & 310 & 0.033 & 0.060 & 0.000 & & 303 & 0.000 & 0.000 & 0.010 \\
\hline & 312 & 0.033 & 0.020 & 0.000 & & 305 & 0.000 & 0.020 & 0.000 \\
\hline & 314 & 0.033 & 0.060 & 0.040 & & 307 & 0.017 & 0.010 & 0.000 \\
\hline & 316 & 0.117 & 0.070 & 0.090 & & 311 & 0.000 & 0.010 & 0.000 \\
\hline & 318 & 0.400 & 0.050 & 0.540 & & 335 & 0.000 & 0.000 & 0.010 \\
\hline
\end{tabular}

For abrreviations, see legend to Table 3.

Differences in genetic diversity were also reflected in the three population samples. Allele frequencies of all 11 loci selected in each sample are presented (Table 4; Figure 2), revealing differences between the samples. However, despite these differences, no clear difference in the average genetic diversity statistics was found among the population samples (Wilcoxon signed-rank test, $\mathrm{P}>0.05$ ).

In total, 31 alleles were found to be unique to a single local population, and $U$ ranged from 5 in the NH population to 15 in the HS population. Despite this, no population possessed a true diagnostic allele.

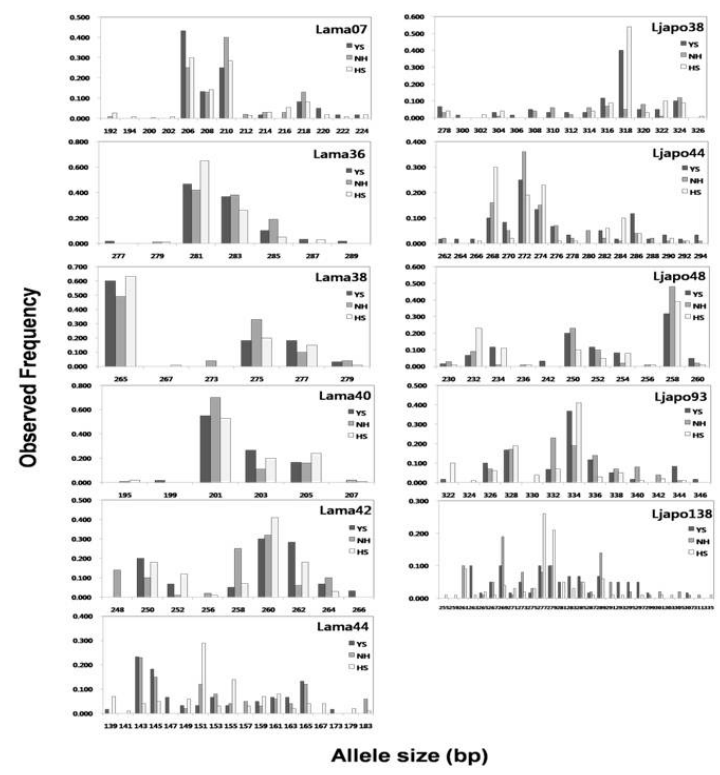

Figure 2. Allele size frequency distributions of the 11 microsatellite loci in the three hatchery populations of Lateolabrax maculatus used in this study. 
The Hardy-Weinberg tests revealed that 27 (82\%) of the 33 locus-population combinations were generally consistent with Hardy-Weinberg proportions; however, six cases exhibited significant deviations from HWE after adjustment of the P values across the 11 loci using the sequential Bonferroni method for multiple observations (Rice, 1989). These six cases resulted from four deficiencies of heterozygotes and two excesses of heterozygotes. Significant deviations were detected at five loci (Lama07, Lama44, Ljapo48, Ljapo93, and Ljapo138). Significant deviations were not evenly distributed among samples or loci, nor were they associated with a particular locus or sample. These deviations were observed at one locus in $\mathrm{NH}$, but at five loci in HS.

The tests of mutation drift equilibrium to detect genetic bottlenecks showed that the YS and NH populations exhibited a heterozygosity excess of microsatellites under the IAM (Wilcoxon test: $\mathrm{P}<0.05$ ) through the Wilcoxon signed-rank test, suggesting a bottleneck in these two hatchery populations.

\section{Population genetic differentiation}

Low but significant genetic differentiation (overall $F_{\mathrm{ST}}=0.027, \mathrm{P}<0.001 ; R_{\mathrm{ST}}=$ $0.012, \mathrm{P}<0.001)$ was observed among three hatchery populations of Korean spotted sea bass. These two statistics with similar results suggested that the level of genetic heterogeneity among these populations was small but statistically significant. Table 5 shows the pattern of genetic differentiation among populations observed by comparing the $D_{\mathrm{CE}}$ value and the mean pairwise $F_{\mathrm{ST}}$ and $R_{\mathrm{ST}}$ values using composite allele frequency data. The pairwise $F_{\mathrm{ST}}$ values among populations were significantly different from zero in all pairwise comparisons (all $\mathrm{P}<0.01$ after sequential Bonferroni's correction). On the other hand, the pairwise $R_{\mathrm{ST}}$ values among populations were significantly different from zero in only one pairwise comparison between NH and HS. The $D_{\mathrm{CE}}$ values were similar to the $F_{\mathrm{ST}}$ and $R_{\mathrm{ST}}$ values, and they ranged from 0.271 to 0.296 . The amount of variation attributable to differences between individuals within populations and within-individual differences were large (3.85 and 93.48, respectively; $\mathrm{P}<0.01)$, while only a low but significant proportion of variation $(2.67 \%$; $\mathrm{P}<$ 0.01 ) was detected among populations (Table 6). The PCA scatter plot based on $D_{\mathrm{CE}}$ values showed that a separate cluster was not formed (Figure 3). In addition, the Mantel test was applied to all samples and revealed no significant relationship between the genetic and geographical distances, invalidating the isolation-by-distance model of genetic structure $(\mathrm{P}>$ $0.05)$. Together, pairwise $F_{\mathrm{ST}}$ and $R_{\mathrm{ST}}$ tests, the Mantel test, and the PCA on the three hatchery populations of L. maculatus did not show a consistent relationship between geographic and genetic distances.

$\begin{aligned} & \text { Table 5. } D_{\mathrm{CE}} \text { distance (below the diagonal) and mean } F_{\mathrm{ST}} \text { and } R_{\mathrm{ST}} \text { estimates (above the diagonal) between each } \\
& \text { pair of three hatchery populations of Korean spotted sea bass (Lateolabrax maculatus). }\end{aligned}$
\begin{tabular}{lccc}
\hline Population & YS & NH & HS \\
\hline YS & - & $0.018^{*}(0.006)$ & $0.019^{*}(0.012)$ \\
NH & 0.275 & - & $0.037^{*}\left(0.015^{*}\right)$ \\
HS & 0.271 & 0.296 & - \\
\hline
\end{tabular}

For abbreviations, see legend to Table 3. 
Table 6. Analysis of molecular variance (AMOVA) of 11 microsatellite loci in three hatchery populations of Korean spotted sea bass (Lateolabrax maculatus).

\begin{tabular}{|c|c|c|c|c|c|}
\hline Source of variation & Degrees of freedom & Sum of squares & Variance components & Percent variation (\%) & $\mathrm{P}$ value \\
\hline Among populations & 2 & 27.682 & 0.113 & 2.67 & 0.000 \\
\hline $\begin{array}{l}\text { Among individuals } \\
\text { within a population }\end{array}$ & 127 & 544.030 & 0.163 & 3.85 & 0.000 \\
\hline Within individuals & 130 & 514.500 & 3.958 & 93.48 & 0.000 \\
\hline Total & 259 & 1086.212 & 4.234 & & \\
\hline
\end{tabular}

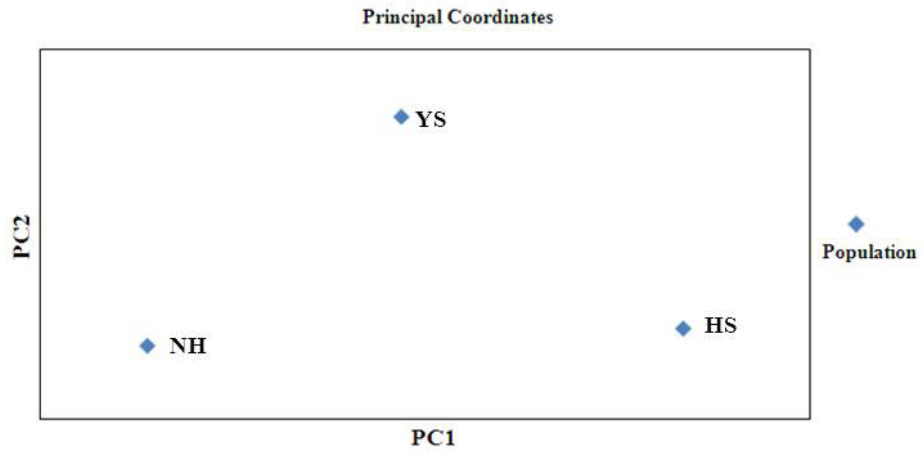

Figure 3. Principal component analysis (PCA) plot showing the phylogenetic relationships among three hatchery samples of the Korean spotted sea bass based on the $D_{\mathrm{CE}}$ (Cavalli-Sforza and Edwards, 1967) genetic distances. The abbreviations are as follows: $\mathrm{YS}=$ Yeosu; $\mathrm{NH}=$ Namhae; and $\mathrm{HS}=$ Hwaseong.

\section{DISCUSSION}

Microsatellite markers, because of their high polymorphism, are ideal for population studies (An et al., 2012). However, microsatellite genotyping is expensive and time consuming. Genotyping cost and time can be greatly reduced by multiplexing. Efficient multiplexing is especially important in situations in which a large number of samples need to be genotyped at multiple loci quickly and cost-effectively. In this study, we tested and developed four threeplex PCRs of 12 microsatellites for efficient genotyping in spotted sea bass.

Multiplex PCR is a demanding reaction, and optimization is needed to balance the amplification of different loci and avoid cross-amplification (Guichoux et al., 2011). We optimized the four three-plex assay by picking the best primer sets, adjusting primer concentrations, and optimizing annealing temperatures to accommodate 12 markers. The optimized protocol worked well with DNA samples. The combination of the simple DNA extraction protocol, which is fast and inexpensive, and microsatellite multiplexing would greatly reduce genotyping cost and turnaround time, allowing highly efficient genotyping of microsatellites. The multiplex PCR method developed in this study was shown to be capable of quantifying the genetic variability of three hatchery populations of Korean spotted sea bass. Our results indicate that it can be used as a fast, robust, and inexpensive tool with high discriminating power to evaluate the variability of $L$. japonicus.

The genetic variability of the 11 microsatellite loci proved to be extensive. The genetic variability in the three hatchery populations (average $A_{\mathrm{R}}=9.32$, average $H_{\mathrm{E}}=0.753$ ) was higher than previous measurements from Chinese natural populations (average $N_{\mathrm{A}}=3$ to 
9, average $H_{\mathrm{e}}=0.405$ to 0.868 at 18 microsatellite loci) (Shao et al., 2009). Similar genetic variability in farmed spotted sea basses $\left(N_{\mathrm{A}}=8.63\right.$, average $H_{\mathrm{E}}=0.724$ at 8 microsatellite loci) was also detected using microsatellite markers (An et al., 2013). An et al. (2013) examined one hatchery and one wild population of L. japonicus in Korea and found that the hatchery population showed very little reduction in genetic variation compared with the wild population, but the genetic heterogeneity between the populations was significant. Because most of the microsatellite markers used were the same, they can be compared on an equal basis. The microsatellite variation determined here was as high or similar to values in this species from other reports, indicating that a high level of genetic variation has been preserved during the domestication of these three cultured spotted sea bass populations in Korea. In Korea, spotted sea bass seeds are produced exclusively in hatcheries. The large number of effective breeders and/or mixing of genetically different lots produced separately might have a significant contribution to the high genetic variation in the populations studied. Not all loci were equally variable. Specifically, Lama44, Ljapo44, and Ljapo138 displayed greater allelic diversity and higher levels of heterozygosity than other loci.

Significant deviations from HWE were observed in 6 of the 33 population-locus cases. Four cases had lower heterozygosity than predicted by HWE. This deficit may be attributed to improper domestication processes in the hatchery populations, such as a limited number of founders, inbreeding, or both (Kohlmann et al., 2005). In addition, the null alleles observed at the microsatellite loci present a likely explanation for the deviation (Callen et al., 1993). In our study, null alleles were observed at 5 of the 12 loci, but the absence of a null allele at the Ljapo93 locus makes this explanation, alone, difficult to reconcile. In contrast, 2 of the 6 significant HWE deviations were caused by an excess of heterozygotes. A decrease in the effective population size can give rise to a reduction in homozygotes because the sampling bias of alleles can result from a small number of parents and differences in allele frequencies between the sexes (Spencer et al., 2000).

Genetic differentiation, detected by $F_{\mathrm{ST}}$ and $R_{\mathrm{ST}}$ values, was low but significant between most pairs of hatchery populations. Although we cannot trace the origins of the significant differences between the hatchery populations without records from the farms, this differentiation observed among cultured populations might have resulted from different founder populations. In addition, different selection procedures in hatchery practices also may have led to changes in the genetic composition of the hatchery populations (Li et al., 2007). Similar results were observed in the microsatellite analysis of other hatchery-reared species including fish (Was and Wenne, 2002; Alarcón et al., 2004). AMOVA of all 11 microsatellites revealed that $2.67 \%\left(F_{\mathrm{ST}}=0.027, \mathrm{P}<0.001\right)$ of the genetic variance occurred among the hatchery samples, with the remainder of the variance occurring between individuals within populations and within individuals. The Mantel test and the PCA scatter plot that was constructed using $D_{\text {CE }}$ genetic distances did not indicate a regional structure, i.e., individuals from nearby regions were not grouped together (Figure 3 ). The relatively low $F_{\mathrm{ST}}$ value and the lack of a relationship between the geographic and genetic distances suggested that some gene flow occurred among populations during the extensive aquaculture of spotted sea bass, although the possibility of widespread exchanges of stocks and eggs between hatcheries by local farmers cannot be excluded.

In conclusion, an understanding of the genetic structure and diversity among marine resources, especially for species for which artificial stocks are produced by hatchery-produced 
seed for natural resource restoration, is critical for the establishment of suitable guidelines for resource management and selective breeding. No detailed information about the genetic diversity of hatchery populations of spotted sea bass in Korea is available to date. In this study, we reported that relatively high genetic variability and significant but minor genetic differentiation were detected among the hatchery populations of spotted sea bass in Korea. Furthermore, the lack of a relationship between the geographic and genetic distances implied extensive spotted sea bass aquaculture. The allelic composition and diversity of spotted sea bass should be carefully considered regarding the seedling and stocking practices of hatcheries in order to conserve the genetic diversity of the natural population. Using the polymorphic microsatellites developed, especially the multiplex set consisting of 12 polymorphic markers, it would be easy to identify individuals to increase the genetic diversity of the existing stocks. Such information will be useful in the genetic management of fisheries and the successful implementation of stock-enhancement programs.

\section{ACKNOWLEDGMENTS}

Research supported by a grant from the Korean National Fisheries Research and Development Institute (NFRDI) (\#RP-2013-BT-082). The views expressed here are those of the authors and do not necessarily reflect the views of NFRDI.

\section{REFERENCES}

Alarcón JA, Magoulas A, Georgakopoulos T, Zouros E, et al. (2004). Genetic comparison of wild and cultivated European populations of the gilthead sea bream (Sparus aurata). Aquaculture 230: 65-80.

An HS, Lee JW and Dong CM (2012). Population genetic structure of Korean pen shell (Atrina pectinata) in Korea inferred from microsatellite marker analysis. Genes Genomics 34: 681-688.

An HS, Lee JW, Kim HY, Kim JB, et al. (2013). Genetic differences between wild and hatchery populations of Korean spotted sea bass (Lateolabrax maculatus) inferred from microsatellite markers. Genes Genomics 35: 671-680.

Antao T, Lopes A, Lopes RJ, Beja-Pereira A, et al. (2008). LOSITAN: a workbench to detect molecular adaptation based on a Fst-outlier method. BMC Bioinformatics 9: 323.

Callen DF, Thompson AD, Shen Y, Phillips HA, et al. (1993). Incidence and origin of "null" alleles in the (AC)n microsatellite markers. Am. J. Hum. Genet. 52: 922-927.

Cavalli-Sforza LL and Edwards AW (1967). Phylogenetic analysis. Models and estimation procedures. Am. J. Hum. Genet. 19: 233-257.

Choi CG and Kim JM (2012). Detection of Laminariaceae species based on PCR by family-specific ITS primers. Fish. Aquat. Sci. 15: 157-162.

Cornuet JM and Luikart G (1996). Description and power analysis of two tests for detecting recent population bottlenecks from allele frequency data. Genetics 144: 2001-2014.

El Mousadik A and Petit RJ (1996). High level of genetic differentiation for allelic richness among populations of the argan tree [Argania spinosa (L.) Skeels] endemic to Morocco. Theor. Appl. Genet. 92: 832-839.

Excoffier L, Smouse PE and Quattro JM (1992). Analysis of molecular variance inferred from metric distances among DNA haplotypes: application to human mitochondrial DNA restriction data. Genetics 131: 479-491.

Excoffier L, Laval G and Schneider S (2005). Arlequin (version 3.0): an integrated software package for population genetics data analysis. Evol. Bioinform. Online 1: 47-50.

Guichoux E, Lagache L, Wagner S, Chaumeil P, et al. (2011). Current trends in microsatellite genotyping. Mol. Ecol. Resour. 11: 591-611.

Han HS, Nam BH, Kang JH, Kim YK, et al. (2012). Genetic variation in wild and cultured populations of the sea squirt Halocynthia roretzi inferred from microsatellite DNA analysis. Fish. Aquat. Sci. 15: 151-155.

Henegariu O, Heerema NA, Dlouhy SR, Vance GH, et al. (1997). Multiplex PCR: critical parameters and step-by-step protocol. Biotechniques 23: 504-511. 
Hong SE, Kim JK, Yu JN, Kim KY, et al. (2012). Genetic variation in the Asian shore crab Hemigrapsus sanguineus in Korean coastal waters as inferred from mitochondrial DNA sequences. Fish. Aquat. Sci. 15: 49-56.

Jiang X, Liao MJ, Liu YJ, Gao TX, et al. (2007). Isolation and characterization of 22 polymorphic microsatellite DNA markers of Japanese sea bass (Laterolabrax japonicus). Mol. Ecol. Notes 7: 492-494.

Kim CH and Jun JC (1997). Provisional classification of temperate sea bass, the genus Lateolabrax (Pisces: Moronidae) from Korea. Korean J. Ichthyol. 9: 108-113.

Kim WJ, Shin EH, Kong HJ, Nam BH, et al. (2013). Development of polymorphic microsatellite markers suitable for genetic linkage mapping of olive flounder Paralichthys olivaceus. Fish. Aquat. Sci. 16: 303-309.

Kohlmann K, Kersten P and Flajšhans M (2005). Microsatellite-based genetic variability and differentiation of domesticated, wild and feral common carp (Cyprinus carpio L.) populations. Aquaculture 247: 253-266.

Lee HJ and Hur SB (2012). Comparison between phylogenetic relationships based on 18S rDNA sequences and growth by salinity of Chlorella-like species (Chlorophyta). Fish. Aquat. Sci. 15: 125-135.

Li Q, Shu J, Yu R and Tian C (2007). Genetic variability of cultured populations of the Pacific abalone (Haliotis discus hannai Ino) in China based on microsatellites. Aquacult. Res. 38: 981-990.

Liu F, Xia JH, Bai ZY, Fu JJ, et al. (2009). High genetic diversity and substantial population differentiation in grass carp (Ctenopharyngodon idella) revealed by microsatellite analysis. Aquaculture 297: 51-56.

Ministry for Food AFaF (2009). Food, Agriculture, Forestry and Fisheries Statistical Yearbook. Ministry for Food, Agriculture, Forestry and Fisheries, Gwacheon.

Neff BD, Fu P and Gross MR (2000). Microsatellite multiplexing in fish. Trans. Am. Fish. Soc. 129: 584-593.

Rice WR (1989). Analyzing tables of statistical tests. Evolution 43: 223-225.

Rousset F (1996). Equilibrium values of measures of population subdivision for stepwise mutation processes. Genetics 142: 1357-1362.

Shao C, Chen S, Xu G, Liao X, et al. (2009). Eighteen novel microsatellite markers for the Chinese sea perch, Lateolabrax maculatus. Conserv. Genet. 10: 623-625.

Spencer CC, Neigel JE and Leberg PL (2000). Experimental evaluation of the usefulness of microsatellite DNA for detecting demographic bottlenecks. Mol. Ecol. 9: 1517-1528.

Støttrup JG and Sparrevohn CR (2007). Can stock enhancement enhance stocks? J. Sea Res. 57: 104-113.

Taniguchi N (2003). Genetic factors in broodstock management for seed production. Rev. Fish Biol. Fisher. 13: 177-185.

Tautz D (1989). Hypervariability of simple sequences as a general source for polymorphic DNA markers. Nucleic Acids Res. 17: 6463-6471.

van Oosterhout C, Hutchinson WF, Wills DPM and Shipley P (2004). MICRO-CHECKER: software for identifying and correcting genotyping errors in microsatellite data. Mol. Ecol. Notes 4: 535-538.

Ward RD (2006). The importance of identifying spatial population structure in restocking and stock enhancement programmes. Fish. Res. 80: 9-18.

Was A and Wenne R (2002). Genetic differentiation in hatchery and wild sea trout (Salmo trutta) in the Southern Baltic at microsatellite loci. Aquaculture 204: 493-506.

Weir BS and Cockerham CC (1984). Estimating F-statistics for the analysis of population structure. Evolution 38: 38 : 1358-1370.

Wilcoxon F (1945). Individual comparisons by ranking methods. Biometrics Bull. 1: 80-83.

Yokogawa K and Seki S (1995). Morphological and genetic differences between Japanese and Chinese sea bass of the genus Lateolabrax. Jpn. J. Ichthyol. 41: 437-455. 